\title{
Estimation of Biomass Heat Storage Using Thermal Infrared Imagery: Application to a Walnut Orchard
}

\author{
Anirban Garai · Jan Kleissl • \\ Stefan G. Llewellyn Smith
}

Received: 29 December 2009 / Accepted: 24 June 2010 / Published online: 15 July 2010

(C) The Author(s) 2010. This article is published with open access at Springerlink.com

\begin{abstract}
A new method to estimate tree biomass heat storage from thermal infrared (TIR) imaging of biomass surface temperature is presented. TIR images of the canopy are classified into trunk, branches, and leaves. The one-dimensional heat equation in cylindrical coordinates is forced with trunk and branch surface temperatures to simulate the temperature distribution and heat storage in tree trunks and branches. Assuming uniform leaf temperatures, heat storage in leaves is computed from the surface temperature of the leaves separately for the sunlit upper and shaded lower canopy. The sum of trunk, branches, leaf, and air heat storage gives the canopy heat storage. Measurements in a walnut orchard near Davis, California, in early June 2007 showed that biomass heat storage was of the same order as air heat storage and about $1 \%$ of daytime and $9 \%$ of nighttime net radiation.
\end{abstract}

Keywords Canopy heat storage $\cdot$ Surface energy balance $\cdot$ Thermal infrared imaging

\section{Introduction}

For a horizontally homogeneous vegetation canopy the surface energy balance reads

$$
R_{\text {net }}=H+L E+S+G
$$

where $R_{\text {net }}$ is the net radiation, $H$ is the sensible heat flux, $L E$ is the latent heat flux, $G$ is soil heat flux at the soil surface (Moore and Fisch 1986), and $S$ is heat storage within the boundaries of the control volume for which the surface energy balance holds, including all biomass and atmospheric constituents between the soil surface and the height of the convective flux measurements. Some investigators (Lindorth and Iritz 1993; Oliphant et al. 2004) choose to include soil heat storage from the surface to the depth of the soil heat-flux measurements (typically $0.05-0.10 \mathrm{~m}$ below the soil surface) in the heat storage term, $S$. However, the large

\footnotetext{
A. Garai · J. Kleissl $(\varangle) \cdot$ S. G. Llewellyn Smith Department of Mechanical and Aerospace Engineering, University of California, San Diego, CA, USA e-mail: jkleiss1@ucsd.edu
} 
thermal mass density of soil then causes a strong dependence of $S$ on the depth of the soil heat-flux plates, making it difficult to compare results between different investigators. Thus we define the control volume's lower boundary to be the soil surface, and exclude soil heat storage from $S$.

Crude approaches to modelling $S$ based on air temperature (e.g. Thom 1975) may give adequate results when the canopy biomass is small, but produce significant errors in dense, thick canopies since canopy temperature then lags air temperature by several hours (Moore and Fisch 1986) and the different masses and temperatures of trunk, branches, and leaves are not considered. Vertical integration of in-situ temperature measurements in the air and the biomass, and humidity measurements in air taken throughout the control volume, allows the direct estimation of $S$. However, a large number of sensors need to be deployed destructively in remote areas and the holes drilled for the in situ temperature sensors may affect the measurement through local changes in heat conductivity. Using these intrusive techniques, several investigators determined $S$ for different vegetation and climate conditions. In a young eucalyptus forest (tree height $h=10 \mathrm{~m}$, biomass density $17.43 \mathrm{~kg} \mathrm{~m}^{-2}$ ) in Australia, Aston (1985) measured the temperature of the trunk of one tree with a diameter at breast height of $0.14 \mathrm{~m}$ at a depth of $0.01-$ $0.07 \mathrm{~m}$ from the surface using thermocouples. This study also included temperature measurements of branches, twigs, leaves, boles, litter, and air at different heights. Aston (1985) found heat storage of up to $50 \mathrm{Wm}^{-2}$ in the morning and up to $-40 \mathrm{~W} \mathrm{~m}^{-2}$ in the evening on a sunny day with maximum net radiation of $700 \mathrm{~W} \mathrm{~m}^{-2}$. Oliphant et al. (2004) measured trunk temperature using 33 thermocouples inserted $0.02 \mathrm{~m}$ into the sapwood of boles, branches and tree trunks between 1.3 and $30.5 \mathrm{~m}$ above ground level (a.g.l.) in a temperate deciduous forest $\left(h=30-40 \mathrm{~m}, 19 \mathrm{~kg} \mathrm{~m}^{-2}\right)$ for three years. $S$ (defined to include $G$ ) reached its maximum around noon, varying from $60 \mathrm{~W} \mathrm{~m}^{-2}$ in April to $20 \mathrm{~W} \mathrm{~m}^{-2}$ in December. Lindorth and Iritz (1993) studied the seasonal effect of bi-hourly $S$ in a short-rotation willow forest in Sweden $(h=4.8 \mathrm{~m}, 2,000$ plants per ha), and found that the maximum $S$ (defined to include $G$ ) during the day ranged from $70 \mathrm{Wm}^{-2}$ in May to $15 \mathrm{Wm}^{-2}$ in August. Moore and Fisch (1986) measured stem and air temperatures of an Amazonian tropical forest $\left(h=35 \mathrm{~m}, 41 \mathrm{~kg} \mathrm{~m}^{-2}\right)$, and solved the heat conduction equation for the trunk by forcing it with air temperature and a convective heat transfer model. They estimated that $S$ can account for up to $80 \mathrm{Wm}^{-2}$, with similar contributions from air temperature, humidity, and biomass heat storage. Over daily intervals, the average heat storage was generally less than $\pm 8 \mathrm{~W} \mathrm{~m}^{-2}$ or $0.7 \mathrm{MJ} \mathrm{m}^{-2}$ day $^{-1}$, which accounted for $3-5 \%$ of daily net radiation.

Methodologically, modelling has focused on solving the heat equation for the biomass with air temperature as a boundary condition (Meesters and Vugts 1996; Jones et al. 2004; Haverd et al. 2007). However, general parameterizations of convection for complex shapes such as trees and complex wind fields such as those in a forest are inaccurate, which introduces uncertainty into previous heat storage modelling results. Non-contact measurements of surface temperature through thermal imaging provide an attractive alternative to forcing the trunk heat equation without the need to parameterize convection. The objective of our study is to estimate biomass heat storage in the canopy by measuring surface temperature changes over the diurnal cycle using infrared thermometry and simulating the trunk temperature distribution using the heat equation. 


\section{Methods}

\subsection{The CHATS Experiment}

The observations were made in a walnut orchard near Dixon, California (about $38.487^{\circ} \mathrm{N}$, $121.845^{\circ} \mathrm{W}$, with a canopy height $h=10 \mathrm{~m}$ ) in 2007, with trees spaced in rows displaced by $7 \mathrm{~m}$. A FLIR ThermaCAM SC3000 TIR camera was placed inside the orchard $239 \mathrm{~m}$ from the northern boundary and over $500 \mathrm{~m}$ from the southern boundary (daytime southerly winds were most common). The lower canopy was imaged with a thermal infrared (TIR) camera facing south-south-west and mounted at a height of $1.68 \mathrm{~m}$, with an inclination of $47^{\circ}$, from 0948 Pacific Daylight Time (PDT) June 8 to 1612 PDT June 10 at 2-min intervals. To obtain the upper leaf temperatures the camera was mounted at a height of $11 \mathrm{~m}$ facing south from 1550 PDT May 28 to 1323 PDT June 4 with an inclination of $15^{\circ}$.

The TIR camera measured radiance at $8-9 \mu \mathrm{m}$ wavelengths with $320 \times 240$ pixels in a field of view of $45^{\circ} \times 60^{\circ}$, and a thermal sensitivity of 0.02 at $30^{\circ} \mathrm{C}$ with an accuracy of $1 \%$. The surface temperature images extracted from the TIR camera were corrected for non-black emissivity of 0.96 for trees and 0.95 for the ground (Sutherland 1986), air transmittance and path radiance. Trunk and leaf pixels were identified from a temporally-averaged temperature map (Fig. 1). By averaging the temperature of all pixels in a specific category, the temporal evolution of leave and branch/trunk surface temperatures was obtained (Fig. 2). Two clear 24-h periods (June 8/9 and May 28/29) with identical mean air temperature $\left(19.3^{\circ} \mathrm{C}\right)$ and similar air temperature spread between daily maximum and minimum $\left(19.8^{\circ} \mathrm{C}\right.$ vs. $\left.18.7^{\circ} \mathrm{C}\right)$ were chosen to merge the above- and below-canopy TIR data.
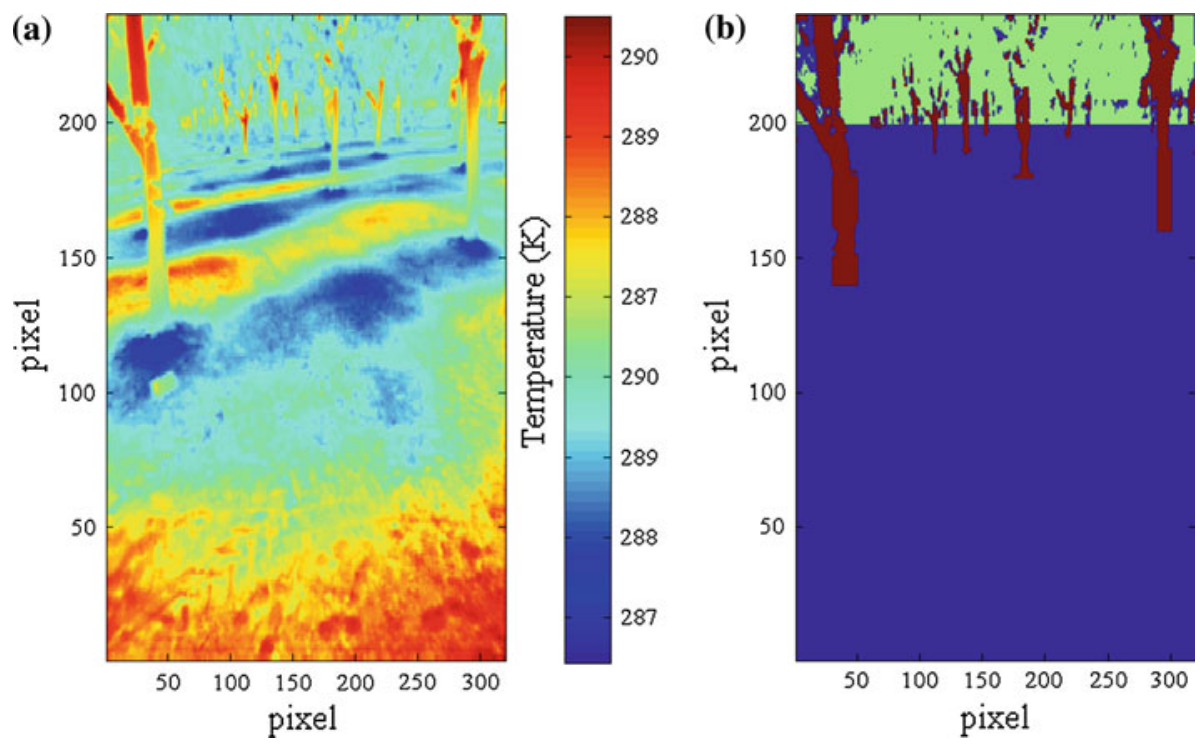

Fig. 1 a Temporally-averaged thermal infrared surface temperature for the set-up at $1.76 \mathrm{~m}$ on June 8, 2007 2000-2200 PDT; b classification of pixels representing tree trunk (brown), leaves (green), and soil (blue) 


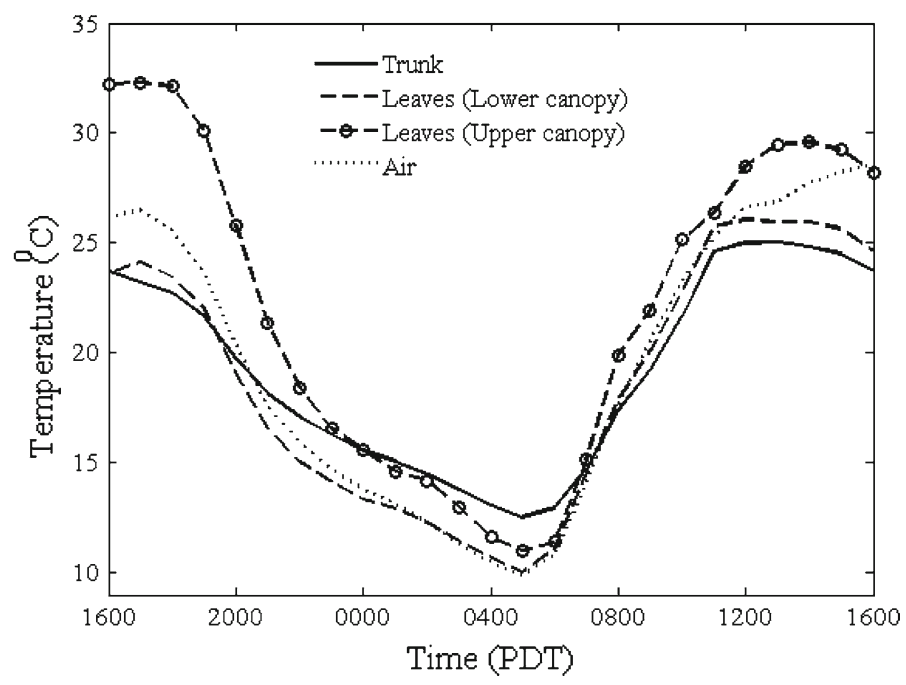

Fig. 2 Trunk, leaf (lower canopy) and air temperature from 1600 PDT June 8 to 1600 PDT June 9 and leaf temperature (upper canopy) from 1600 PDT May 28 to 1600 PDT May 29

Air temperature and relative humidity profiles, as well as $H, G$, and $L E$ values, were obtained from the Canopy Horizontal Array Turbulence Study (CHATS, Patton et al. 2008), a set-up with aspirated temperature and humidity probes, and eddy-covariance flux (EC) measurements at 10 heights on a 30 -m tower located in the orchard $116 \mathrm{~m}$ north of the TIR camera. In this study we use $L E$ and $H$ from the EC sensors at $z=15 \mathrm{~m}$, and $T_{\text {air }}$ and specific humidity $w$ from the aspirated thermocouples and humidity sensors at 1.5, 3, 4.5, 6, 7.5 and $9 \mathrm{~m}$. $G$ was estimated from a REBS HFT-3 soil heat-flux plate at $0.05-\mathrm{m}$ depth where heat storage in the soil between the soil heat flux plate and the ground surface was obtained through a Hukseflux TP01 thermal property probe and soil temperature measurements at $0.05 \mathrm{~m}$ depth.

\subsection{Biomass Quantity and Thermal Properties}

To estimate the biomass, trunk and branch diameters were measured at six different heights from 0 to $2 \mathrm{~m}$ for four trees in the field-of-view of the TIR camera. The average and standard deviation of the diameter at breast height were $0.278 \pm 0.023 \mathrm{~m}$. Then the biomass of trunk and branches per horizontal area at different heights were estimated assuming a density of wood $\left(\rho_{\text {wood }}\right)$ of $800 \mathrm{~kg} \mathrm{~m}^{-3}$, moisture content $m=50 \%$ (Moore and Fisch 1986), and the measured number of trees per unit horizontal area $\mathrm{N}=0.02$ trees $\mathrm{m}^{-2}$. In the absence of direct allometric measurements above $2 \mathrm{~m}$, we estimated branch thickness assuming the total branch biomass decreased linearly with height and that the number of branches doubled for each $2 \mathrm{~m}$ increase in height. The leaf biomass was estimated to be $2 \%$ of total woody (trunk and branches) biomass for mixed hardwood plant type (Jenkins et al. 2003). We found total tree biomass of $7.24 \mathrm{~kg} \mathrm{~m}^{-2}$, comprised of $2.89 \mathrm{~kg} \mathrm{~m}^{-2}$ of trunk, $4.21 \mathrm{~kg} \mathrm{~m}^{-2}$ of branches and $0.142 \mathrm{~kg} \mathrm{~m}^{-2}$ of leaf biomass. The specific heat capacity $\left(C_{p \text {,trunk }}\right)$, thermal conductivity $(k)$ and thermal diffusivity $(\alpha)$ of woody biomass were estimated as $2546.0 \mathrm{~J} \mathrm{~kg}^{-1} \mathrm{~K}^{-1}, 0.38 \mathrm{~W} \mathrm{~m}^{-1} \mathrm{~K}^{-1}$ and $1.244 \times 10^{-7} \mathrm{~m}^{2} \mathrm{~s}^{-1}$, respectively (Moore and Fisch 1986). The specific heat capacity of leaves $C_{p}$, leaf is assumed to be $2760 \mathrm{~J} \mathrm{~kg}^{-1} \mathrm{~K}^{-1}$ (Aston 1985). 


\subsection{Estimation of Heat Storage}

The total heat storage $S$ is computed from the sum of heat storage in the trunk, branches, leaves and air, $S=S_{\text {trunk }}+S_{\text {branch }}+S_{\text {leaf }}+S_{\text {air }}$, where $S_{\text {air }}$ is the sum of the heat storage in dry air and water vapour as in Oliphant et al. (2004, their Eqs. 5 and 6). The heat storage in leaves is given by

$$
S_{\text {leaf }}=m_{\text {leaf }} C_{\text {p, leaf }} \frac{d T_{\text {leaf }}}{d t},
$$

where $T_{\text {leaf }}$ is the average leaf temperature. Assuming a cylindrical tree trunk with height $h$ and radius $R_{\text {out }}$, the heat storage in the trunk can be estimated using

$$
\begin{aligned}
& S_{\text {trunk }}=m_{\text {trunk }} C_{p, \text { trunk }} \frac{d T_{\text {trunk }}}{d t} \cong \\
& m_{\text {trunk }} C_{p \text {,trunk }} \frac{\left\{\left(\int_{0}^{1} 2 \bar{r} T_{\text {trunk }} d \bar{r}\right)_{t=t_{2}}-\left(\int_{0}^{1} 2 \bar{r} T_{\text {trunk }} d \bar{r}\right)_{t=t_{1}}\right\}}{t_{2}-t_{1}}
\end{aligned}
$$

where $m_{\text {trunk }}\left(=\pi R_{\text {out }}^{2} h \rho_{\text {wood }} N\right)$ is the biomass density of the trunk, $C_{p \text {, trunk }}$ is the specific heat capacity of the trunk, $T_{\text {trunk }}$ is the temperature within the trunk, and $\bar{r}$ is the radial distance normalized by $R_{\text {out }}$. The heat storage in branches $\left(S_{\text {branch }}\right)$ is also calculated using Eq. 3.

To obtain the hourly biomass heat storage in the tree trunk and branches for a typical clear summer day, the trunk and branch transient temperature profile $T(r)$ is modelled as an infinite cylinder whose surface temperature is periodic with time. If TIR images of the tree from multiple aspects were available, the full three-dimensional heat equation with $T(r, \theta, z)$ could be modelled. However, a static TIR camera location is advantageous for data continuity and pixel classification. The dense canopy (leaf area index $=2$ ) provided near-complete shading of the trunk and branches, so other aspects are not expected to be much warmer than the measured northerly aspect in daytime. Assuming the average tree pixel temperature $(f(t)$, Fig. 2) provided a homogeneous surface boundary condition, and non-dimensionalizing the radial coordinate by the tree radius $R_{\text {out }}$, the governing equation is

$$
\frac{\alpha}{R_{\text {out }}^{2}}\left\{\frac{\partial^{2} T}{\partial \bar{r}^{2}}+\frac{1}{\bar{r}} \frac{\partial T}{\partial \bar{r}}\right\}=\frac{\partial T}{\partial t}
$$

The initial conditions are at $t=0, T=$ constant, the boundary conditions are at $\bar{r}=0$, $T$ is finite, and at $\bar{r}=1, T=f(t)$. Given the persistent meteorological conditions, the trunk temperature is expected to change periodically with a period of 1 day. Thus to fit a periodic $f(t)$ to the trunk surface temperature data in Fig. 2 we used a 20th-order Fourier cosine series with coefficients $A_{n}$. Then Eq. 4 was solved using the separation of variables and superposition theorem (Eckert and Drake 1972; Khedari et al. 1992), yielding the trunk temperature

$$
T(\bar{r})=A_{0}+\sum_{n=1}^{n=20} A_{n} \operatorname{Re}\left[e^{-n i \pi t} \frac{J_{0}\left(e^{-i^{1.5}} n R_{\mathrm{out}} \sqrt{\frac{\omega}{\alpha} \bar{r}}\right)}{J_{0}\left(e^{-i^{1.5}} n R_{\mathrm{out}} \sqrt{\frac{\omega}{\alpha}}\right)}\right],
$$

where $\omega=\pi$. The solution was coded into MATLAB (The Mathworks, Inc.) and validated with a steady oscillation of a periodic cosine shaped boundary condition on the wall of an infinite cylinder (Khedari et al. 1992, p. 322). 


\section{Results and Discussion}

\subsection{Temperature Distribution in the Tree Trunk}

Figure 3 depicts the temperature profile of a tree trunk of radius $0.134 \mathrm{~m}$ at different times of the day, and shows that the change in temperature at the trunk surface propagates into the trunk. The temperature variation inside the tree lags the variation at the surface by several hours. From time series of trunk temperature at different depths within the tree (not shown) of $[0,25,50,75] \%$ of $R_{\text {out }}$ from the trunk surface the phase lags are found to be $[0,2,3,5]$ hours whereas the amplitude of temperature fluctuations are $[12,8,5,4]{ }^{\circ} \mathrm{C}$ respectively.

\subsection{Heat Storage}

From TIR measurements of trunk, branch, and leaf temperatures and thermal modelling inside tree and branches, hourly values of storage $S$ in air, trunks, branches and leaves in the walnut orchard were estimated (Fig. 4). Since temporal gradients in temperature drive heat storage, most heat is released (negative heat storage) from trunk and branches during the cooling period after sunset (1900 PDT). With the increase in temperature after sunrise (0500 PDT) the heat storage becomes positive; $S_{\text {trunk }}+S_{\text {branch }}$ are found to vary between $12 \mathrm{~W} \mathrm{~m}^{-2}$ at $1000 \mathrm{PDT}$ and $-6 \mathrm{~W} \mathrm{~m}^{-2}$ at $1900 \mathrm{PDT}$, while $S_{\text {leaf }}$ varies between $0.5 \mathrm{~W} \mathrm{~m}^{-2}$ at $0700 \mathrm{PDT}$ and $-0.4 \mathrm{~W} \mathrm{~m}^{-2}$ at $1900 \mathrm{PDT}$. The time of maximum $S_{\text {leaf }}$ is $3 \mathrm{~h}$ earlier than that of the trunk and branches, since leaves have a higher surface area to volume ratio. Thus maximum and minimum $S_{\text {leaf }}$ occurs shortly after sunrise and sunset, coincident with the increase and decrease in air temperature.

$S / R_{\text {net }}$ is constant at about $1 \%$ during the middle of the day (1100-1600 PDT), and 9\% around midnight (2300-0400 PDT) while biomass heat storage $S_{\text {biomass }}\left(=S_{\text {trunk }}+S_{\text {branch }}+\right.$

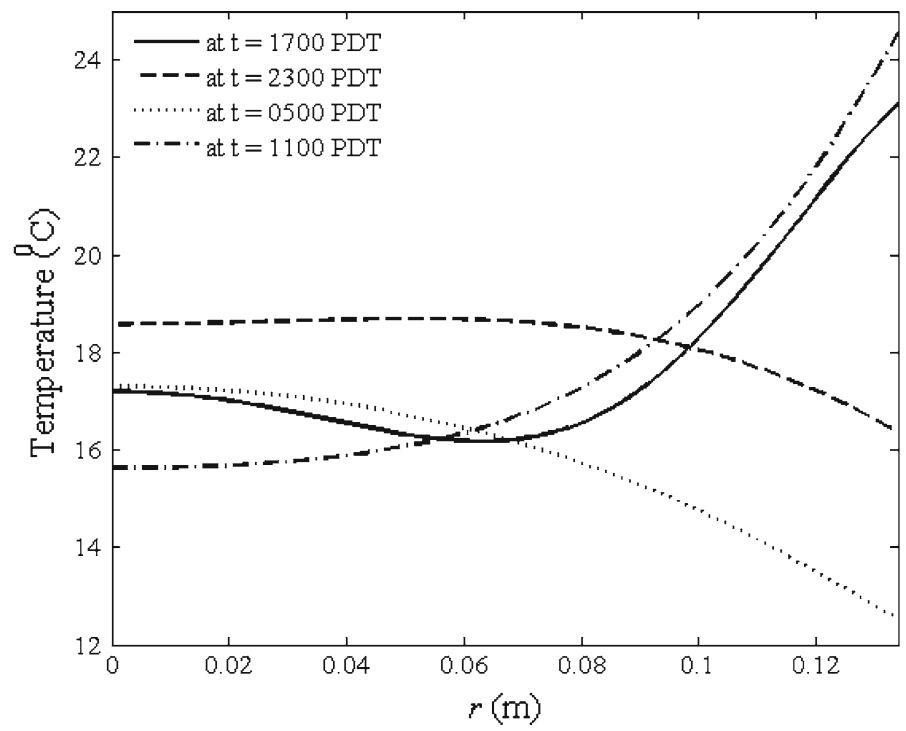

Fig. 3 Trunk temperature profile as a function of radial distance at different times 

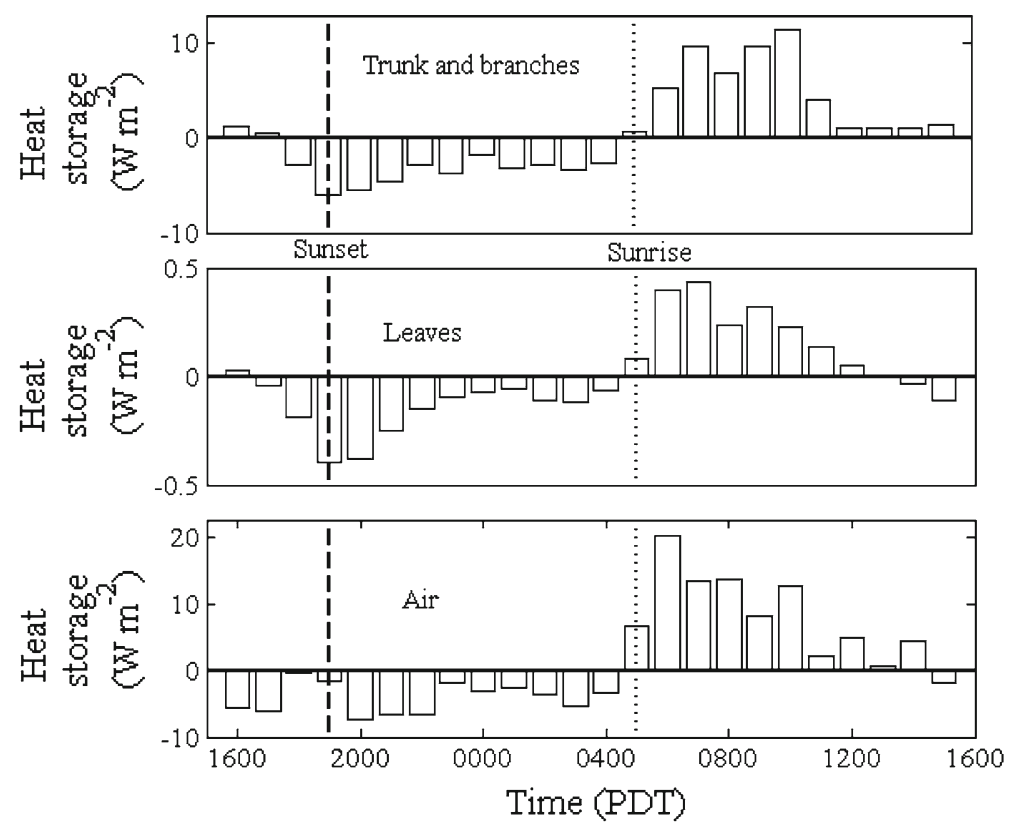

Fig. 4 Hourly average of heat storage in trunk and branches, leaves and air from June 81600 to June 91600 PDT

$\left.S_{\text {leaf }}\right)$ is $0.2 \%$ of $R_{\text {net }}$ around midday and $4 \%$ of $R_{\text {net }}$ around midnight. In terms of the maximum hourly $R_{\text {net }}\left(723 \mathrm{~W} \mathrm{~m}^{-2}\right)$, the largest amount of storage $S$ is $0.036 R_{\text {net }}$ at 0600 PDT and the largest $S_{\text {biomass }}$ is $0.016 R_{\text {net }}$ at 1000 PDT.

\subsection{Sensitivity Analysis}

Here we have derived a general method to derive biomass heat storage from surface temperature observations and applied it to measurements in a walnut orchard. While the tree diameter, biomass density, temperature amplitude, and tree thermal properties may change in different ecosystems and climate zones, we would expect the shape of the diurnal temperature fluctuation to be similar for any shaded tree trunk. For a given tree diameter, biomass density enters linearly in the heat storage calculation. Thus our results could easily be recalculated for a different biomass density. However, heat thermal diffusivity $(\alpha)$, tree diameter, and temperature amplitude may enter non-linearly into the heat storage equation. To generalize our results and allow other investigators to apply them to their sites, we conducted simulations for different parameter values, namely the moisture content $m$, thermal conductivity $k$, trunk radius $R_{\text {out }}$ and the amplitude of diurnal temperature fluctuations.

For a biomass of $7 \mathrm{~kg} \mathrm{~m}^{-2}$ as in our orchard we simulated different tree distributions ranging from a large number of thin trees to a small number of thick trees and different $m$. Figure 5 depicts the daily maximum of hourly trunk heat storage $\left(S_{\max }\right)$ for varying tree-trunk radius $R_{\text {out }}$ and $m$. For a given $R_{\text {out }}, S_{\max }$ increases with increasing $m$. For a given $m$ the trunk heat storage decreases with increasing $R_{\text {out }}$ as the heat penetration depth and the total biomass exposed to diurnal temperature fluctuations decrease. At $m=0.5$ the sensitivity of $S_{\max }$ to $m$ is a $5 \%$ change in $S_{\max }$ for a $10 \%$ change in $m$. 


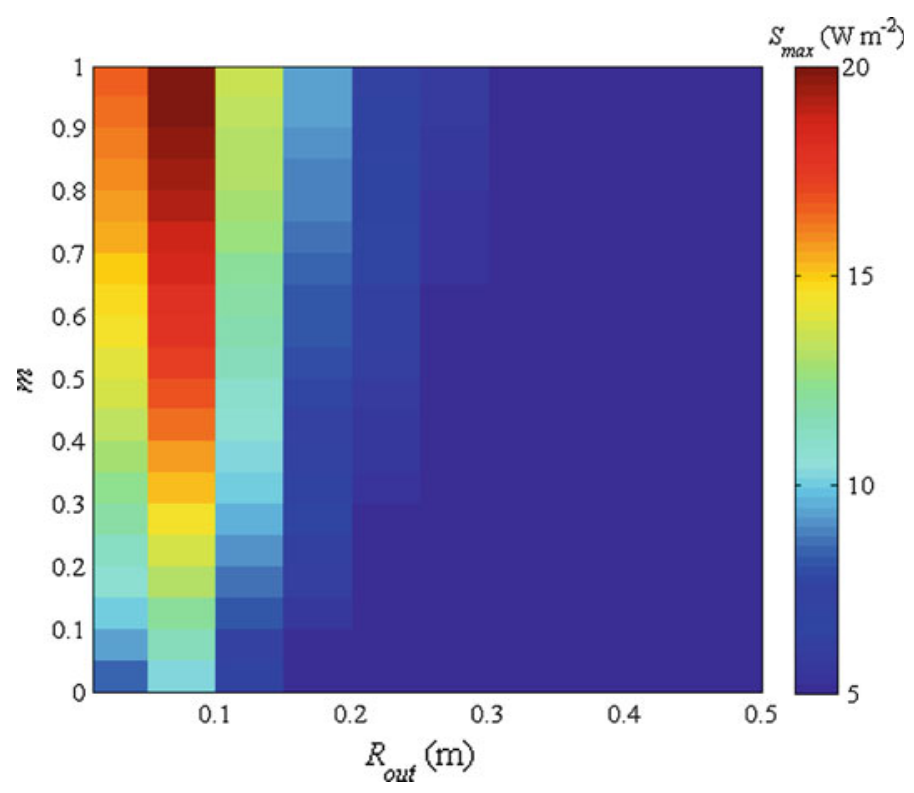

Fig. 5 Maximum hourly trunk heat storage $\left(\mathrm{W} \mathrm{m}^{-2}\right)$ for different trunk radii $R_{\text {out }}$ and moisture content $m$ in a forest with a biomass density of $7 \mathrm{~kg} \mathrm{~m}^{-2}$, tree height $10 \mathrm{~m}$ and the trunk surface temperature evolution of Fig. 2

A change in the thermal conductivity $k$ with constant $\left(\rho_{\text {wood }} C_{p \text {,trunk }}\right)$ also affects the thermal diffusivity $\alpha$. Since we used an empirical equation to calculate $k$ we examined the sensitivity of $S_{\max }$ to $k$. For the tree diameter in the walnut orchard, increasing $k$ by $20 \%$ produces an increase in $S_{\max }$ by $20 \%$, while decreasing $k$ by $20 \%$ produces a $25 \%$ decrease in $S_{\max }$.

By varying the amplitude of the diurnal temperature fluctuations we observed a nearlinear effect on trunk heat storage, primarily because the heat penetration thickness in the tree trunk does not depend on diurnal temperature fluctuations. The diurnal temperature fluctuations increase the $\partial T / \partial t$ term in the heat storage expression almost linearly, producing an almost linear increase in the trunk heat storage.

\section{Conclusions}

In this study we have developed and applied a novel method for quantifying biomass heat storage using thermal infrared (TIR) imaging as a boundary condition to drive the trunk heat equation. This is a major advance compared to the modelling of convection between biomass and air and the laborious and destructive in-situ installation of numerous contact temperature sensors, which have to be carefully placed to capture the annular portion of the trunk where the majority of the heat storage occurs. This experimental technique can be extended for the assessment of heat storage in buildings from measurements of wall and roof surface temperatures.

In a walnut orchard with a biomass density of $7 \mathrm{~kg} \mathrm{~m}^{-2}$ the canopy heat storage term is dominated by air heat storage and woody biomass heat storage, while the leaf heat storage is negligible. On average, the total heat storage term is about $1 \%$ of net radiation around 
midday and $9 \%$ of net radiation around midnight. The total heat storage can be up to $3.6 \%$ of maximum net radiation while the biomass heat storage is up to $1.6 \%$ of maximum net radiation. Around sunset and sunrise when $R_{\text {net }}$ is small, heat storage is larger than $R_{\text {net }}$ but even then heat storage remains a small absolute value. The analysis also allows computation of response time constants for different components of the canopy with respect to canopy air temperature. This has applications in areas such as the computation of respiratory terms in the carbon balance of the plant. During the daytime, the response time constant of the average trunk temperature is about $8 \mathrm{~h}$ delayed compared to the canopy air temperature. For the lower and upper canopy leaves the time constant was -0.1 and $-0.5 \mathrm{~h}$, respectively, indicating that leaf temperatures increase and decrease earlier than air temperature.

In our study we made the following assumptions: (1) The heat equation was solved in one dimension only as a function of radius, and forced by the average trunk pixel surface temperature. In practice, however, the temperature profile of the tree trunk and heat storage term in the trunk will be functions of height and aspect. To acquire sufficient TIR images, depending on the temporal variability of the radiative forcing, the camera could be rotated around the tree at least once per hour. (2) Allometric measurements were only conducted below $2 \mathrm{~m}$ height and models were used to determine woody biomass above and leaf biomass. (3) Thermal properties of trees were assumed to be constant, which might not be true for trees with thick bark and potential air gaps between the bark and inner wood. In those cases thermal properties should be considered as a function of trunk radius. (4) We did not consider the heat loss term due to sap flow in the trunk heat storage term explicitly; sap flow causes cooling of the lower part of the trunk compared to the upper part. By taking the average temperature of all trunk and branch pixels we implicitly accounted for the cooling effect of sap flow, which we estimate to be as high as $1.6 \mathrm{~W} \mathrm{~m}^{-2}$ of the surface area in our orchard.

Acknowledgements The analysis of the data was funded by NSF-EAR0739109. We would like to express our gratitude to Jan Hendrickx for the TIR camera, and Yoichi Shiga, Michael Sankur, and Mandana Farhadieh for field assistance. The experiment would not have been possible without the support of the NCAR Earth Observing Laboratory staff under the leadership of Ned Patton and Tom Horst. Thanks to Antonio Parades, the Cilker family, and Roy Gill for providing access to their orchards. The MATLAB program used to conduct these analyses is provided in the online material associated with this article.

Open Access This article is distributed under the terms of the Creative Commons Attribution Noncommercial License which permits any noncommercial use, distribution, and reproduction in any medium, provided the original author(s) and source are credited.

\section{References}

Aston AR (1985) Heat storage in a young eucalypt forest. Agric For Meteorol 35:281-297

Eckert ERG, Drake RM (1972) Analysis of heat and mass transfer. McGraw Hill Series in Mechanical Engineering, New York, pp 208-216

Haverd V, Cuntz M, Leuning R, Keith H (2007) Air and biomass heat storage fluxes in a forest canopy: calculation within a soil vegetation atmosphere transfer model. Agric For Meteorol 147(3-4):125-130

Jenkins JC, Chojnacky DC, Heath LS, Birdsey RA (2003) Comprehensive database of diameter-based biomass regression for North American tree species. United States Department of Agriculture, Forest Service, Northeastern Research Station. General Technical Report NE-319

Jones JK, Webb BW, Jimenez D, Reardon J, Butler B (2004) Development of an advanced one-dimensional stem heating model for application in surface fires. Can J For Res 34(1):20-30

Khedari J, Benigni P, Rogez J, Mathieu JC (1992) A solution of the heat conduction equation in the finite cylinder exposed to periodic boundary conditions: the case of steady oscillation and thermal property. Proc Roy Soc Lond A 438:319-329 
Lindorth A, Iritz Z (1993) Surface energy budget dynamics of short rotation willow forest. Theor Appl Climatol 47:175-185

Meesters AGCA, Vugts HF (1996) Calculation of heat storage in stems. Agric For Meteorol 78:181-202

Moore CJ, Fisch G (1986) Estimating heat storage in Amazonian tropical forest. Agric For Meteorol 38: 147-169

Oliphant AJ, Grimmond CSB, Zutter HN, Schmid HP, Su HB, Scott SL, Offerle B, Randolph JC, Ehman J (2004) Heat storage and energy balance fluxes for a temperature deciduous forest. Agric For Meteorol 126:185-201

Patton EG, Horst T, Lenschow D, Sullivan P, Oncley S, Burns S, Guenther A, Held A, Karl T, Mayor S, Rizzo L, Spuler S, Sun J, Turnipseed A, Allwine E, Edburg S, Lamb B, Avissar R, Holder H, Calhoun R, Kleissl J, Massman WJ, Paw UKT (2008) The Canopy Horizontal Array Turbulence Study (CHATS). In: 18th symposium on boundary layers and turbulence. Stockholm, Sweden

Sutherland (1986) Broadband and spectral emissivities $(2-18 \mu \mathrm{m})$ of some natural soil and vegetation. J Atmos Ocean Technol 3:199-202

Thom AS (1975) Momentum, mass and heat exchange of plant communities. In: Monteith JL (ed) Vegetation and the atmosphere, vol 1. Academic Press, London, pp 57-109 